\title{
Orientaciones actuales de la política migratoria con una visión desde el Sur global
}

\author{
Current orientations of the migratory policy \\ with a vision from the global South
}

Arturo Nieto Mendoza*

ISSN IMPRESO 1870-7599 | ISSN RED CÓMPUTO 2448-7783 | 107-131

RECIBIDO 17/01/19 | ACEPTADO 02/03/19

Resumen. Actualmente, las políticas migratorias tienen tres orientaciones: a) de fronteras accesibles y derechos humanos, que ponen en el centro ese conjunto de garantías sustentadas en la dignidad humana; b) de fronteras restrictivas de control y securitización, enfocadas hacia un control férreo de las fronteras y que incluyen a la migración en la agenda de seguridad; yc) de fronteras expandidas y externalización, con respecto a las políticas que implementan los países de destino dejando de lado su responsabilidad y ejerciendo una presión asimétrica hacia países de origen y tránsito con la intención de influir en los flujos migratorios. El artículo expone, además, una visión de cómo entender las políticas con una perspectiva desde el Sur global para las migraciones.

Palabras clave: política migratoria, Sur global, control fronterizo, externalización, derechos de migrantes.

\begin{abstract}
Current trends in migratory policies can be summarized as: a) accessible borders and human rights, which puts at the center that set of guarantees based on human dignity; b) restrictive borders of control and securitization, which focuses on a tight control of borders, putting migration on the security agenda; and c) expanded borders and outsourcing, which refer to the policies that the countries of destination implement, abdicating their responsibility and exerting asymmetric pressure towards the countries of origin and transit with the intention of influencing migration flows. In addition, it offers a perspective of how to understand policies with a perspective on migration from the global South.
\end{abstract}

Keywords: migration policy, global South, border control, externalization, migrant rights.

\footnotetext{
* Mexicano. Maestro en Gobierno y Asuntos Públicos y doctorante en el Programa de Ciencias Políticas y Sociales de la UNAM. Correo-e: nietoarturo@politicas.unam.mx
} 


\section{Introducción}

La migración no debería entenderse desde una perspectiva estática, lineal o uniforme, pues responde a diferentes factores (económicos, políticos, sociales, demográficos y culturales), lo que conlleva a una reconfiguración en el tiempo. Ejemplo de ello es que «hoy vemos cómo muchos países que sólo se caracterizaban por enviar, emitir o desalojar a sus ciudadanos/as hacia otros países, se convierten en receptores de migrantes internacionales y transcontinentales» (Mora, 2013:14). En consecuencia, las políticas migratorias se transforman en el tiempo más allá de una posición política o económica.

En las últimas décadas, los Estados han buscado influir sobre los flujos migratorios, dependiendo de sus intereses, al incentivar o desincentivar la migración de personas, al atraer talento o al exportarlo; y con el tiempo, han vuelto más restrictiva y selectiva la entrada de migrantes y posibles solicitantes de refugio a su territorio. Pero, «existe una contradicción manifiesta entre las necesidades que los países desarrollados tienen de población migrante, para contribuir a su crecimiento económico y al rejuvenecimiento de su población, y el tono restrictivo con el que tradicionalmente han regulado los flujos migratorios» (Alonso, 2011:43). Dicha contradicción se expresa en las políticas migratorias de los Estados, de ahí que este trabajo busque responder żqué orientaciones de política migratoria predominan en el contexto migratorio actual? ’̇cómo impactan estas políticas en el Sur global?

\section{La política migratoria}

En la política migratoria como «en ningún otro ámbito de acción del Estado se definen los contornos y el contenido sustantivo de la democracia, y es que los migrantes tensionan la promesa de un régimen basado en el acceso igualitario a los derechos para los habitantes de un territorio" (Thayer, 2016:2). De ese modo, los migrantes exigen un espacio, visibilidad y respeto a sus derechos humanos en una democracia que no debería excluirlos, marginarlos o criminalizarlos.

La Corte Interamericana de Derechos Humanos (CIDH, 2003) define la política migratoria de un Estado: «Constituida por todo acto, medida u omisión institucional (leyes, decretos, resoluciones, directrices, actos administrativos, 
etcétera) que versa sobre la entrada, salida o permanencia de población nacional o extranjera dentro de su territorio» (2003). Las políticas migratorias tienen que ver con las decisiones públicas y los cursos de acción que toma una autoridad con una orientación determinada acerca de inmigración, emigración y tránsito de personas.

En efecto, el instrumento primordial de los gobiernos es la formulación e implementación de políticas migratorias que actúan en forma específica sobre las tendencias de ciertos flujos de población, sus consecuencias o algunas de sus causas inmediatas (Mármora, 2002). No obstante, el alcance es limitado, pues no se modifican las causas estructurales que definen los principales movimientos migratorios. En ese sentido, Peter Kivisto y Thomas Faist exponen:

Los gobiernos son responsables de promulgar políticas que en última instancia determinen quién ingresa y quién no. Determinan los criterios por los cuales las entradas potenciales serán aceptadas o rechazadas. Además, los Estados son responsables de hacer cumplir las leyes de inmigración, lo que incluye tratar con personas que ingresan a países sin permiso legal para hacerlo. Cuando se resume de manera tan sucinta, está claro que los Estados desempeñan un papel importante en la configuración de los flujos de inmigración (2010:195).

Por tanto, el papel de los Estados sigue siendo fundamental en la formulación e implementación de la política migratoria; sin embargo, ha dejado de ser el único actor clave para la definición, aplicación y evaluación de las políticas en materia migratoria, pues se han incorporado actores relevantes en su formulación y ejecución que van cobrando mayor influencia.

Además, la migración se transforma: «La denominada migración transitoria ha ganado importancia en lo que va del presente siglo, así como los movimientos migratorios circulares y, muy particularmente, las migraciones temporales» (Mora, 2013:14). Por tanto, la modalidad de una política migratoria corresponde al modo en que ésta se presenta, entre las que resaltan las siguientes:

Políticas programáticas y coyunturales. Se diferencian, básicamente, por el planteo que adopta la respuesta institucional frente al fenómeno migratorio. Si la respuesta se da en el contexto de un proyecto político, económico o social, se trata de políticas programáticas. Si la respuesta es una reacción a la presión migratoria del momento, corresponde entonces a políticas coyunturales. 
Políticas explícitas o implícitas. Cuando la institucionalización de una política migratoria se formaliza en cuanto a sus objetivos y acciones a través del discurso oficial o de la legislación pertinente, se trata de una política migratoria explícita. La carencia de esta formalización implica que las medidas asumidas se basan en concepciones implícitas de los objetivos de las políticas migratorias vigentes y que, de ninguna manera, determinan su no existencia. En algunos casos se puede observar que existen políticas generales explícitamente formuladas, pero que en la práctica se traducen en acciones no coincidentes con los objetivos enunciados debido a que en la aplicación se ejecutan políticas implícitas de signo contrario (Mármora, 2002:84-88).

La falta de una consistencia entre la política y la gestión migratoria trae consigo resultados imprevistos. Al respecto, Lelio Mármora (2002) expone que una política definida como explícitamente abierta en el discurso y en la legislación general, pero cerrada y restrictiva en la gestión migratoria cotidiana, puede producir una masa de inmigrantes ilegales, atraídos por una apelación que luego en la realidad no se concreta.

Por ello, las luchas desde la sociedad civil y las intencionalidades de las políticas son clave, las dinámicas migratorias diferirán si la finalidad es de retención (evitar la salida del país de origen), promoción (incentivar la salida o permanencia), regulación (restricción o conducción de flujos), recuperación (repatriación) e incorporación (adecuada inserción) (Mármora, 2002).

En opinión de Mathias Czaika y Hein de Haas (2013), las políticas de migración se establecen con el fin de afectar el comportamiento de una población objetivo (es decir, potenciales migrantes) en una dirección deseada. Consideran que muchas políticas no suelen ser vistas como políticas de migración; sin embargo, influyen en la migración y en ciertos casos sus efectos pueden ser mayores que los de las políticas de inmigración selectivas. Los ejemplos incluyen el mercado laboral, la macroeconomía, el sector militar, el ámbito de bienestar y ayuda.

Entonces, las políticas migratorias implementadas por los Estados son solamente una parte de la acción estatal que influye sobre los flujos migratorios de forma directa, dado que otro tipo de políticas puede favorecer o desincentivar la migración o tránsito en un país. Esto lleva a tener un objetivo claro para su formulación junto con una visión amplia del accionar gubernamental en sus diferentes esferas de acción. 


\section{Orientaciones de la política migratoria}

Existen en la actualidad dos orientaciones dominantes en la política migratoria y una tercera va adquiriendo gran fuerza; la primera se vincula con una política de respeto a los derechos humanos; la segunda, con políticas hacia el control y la securitización; y una tercera la constituyen las políticas de externalización (como se muestra a continuación).

\section{FIGURA 1}

Orientaciones predominantes de la política migratoria

Fronteras expandidas

y externalización migratoria

Fronteras accesibles y derechos humanos

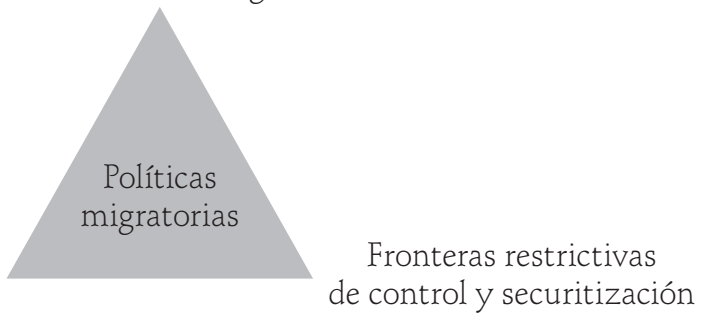

Fuente: elaboración propia.

Orientación de fronteras accesibles y derechos humanos

Durante y posterior a la Guerra Fría, los derechos humanos, cuya protección está estrechamente vinculada al proceso de democracia, se reconocieron como un asunto internacional mediante el establecimiento de normas universales y mecanismos para mantenerlas. Así, mientras que plantear el tema de los derechos humanos en un Estado soberano alguna vez se consideró una interferencia en sus asuntos internos, hoy la comunidad internacional ha aceptado que la promoción de los derechos del individuo es una de las tareas de la Organización de las Naciones Unidas (Boutros-Ghali, 1995).

La Declaración Universal de los Derechos Humanos señala lo siguiente:

1. Toda persona tiene derecho a circular libremente y a elegir su residencia en el territorio de un Estado.

2. Toda persona tiene derecho a salir de cualquier país, incluso el propio, y a regresar a su país. 
Antoine Pécoud y Paul de Guchteneire advierten que «la emigración y la inmigración están inextricablemente vinculadas entre sí, y en cierto modo la Declaración Universal de Derechos Humanos se ha quedado a medio camino en su reconocimiento del derecho a circular» (2008:23). El derecho de inmigrar se queda vacío frente a la facultad de los Estados de controlar el ingreso, la residencia y salida de migrantes. En nuestros tiempos, la movilidad humana se ha convertido en un fenómeno más global y frecuente, pero las distinciones clásicas sobre la migración, voluntaria o forzosa, regular o irregular, temporal, estacional, a largo plazo o permanente, son menos claras. Esto hace que sea mucho más convincente el argumento de que los derechos de todos los migrantes deben abordarse de manera integral, independientemente de los motivos para migrar (OIT, 2015).

La finalidad de los derechos humanos es proteger a las personas migrantes, como a cualquier otra persona, «de los abusos de parte de los Estados e interferencias de sus derechos. Los derechos humanos, por ejemplo, no se basan en la nacionalidad sino en la individualidad, y protegen tanto a los nacionales como a los migrantes» (Pécoud y De Guchteneire, 2008:36).

Los Estados suscriben instrumentos de derechos humanos ${ }^{1}$ y se comprometen no sólo a garantizar la seguridad física de toda persona dentro de su territorio, sino a integrarlas en actividades económicas y culturales, lo que da lugar a una serie de derechos inmanentes. En ese sentido, la CIDH (2003) explica que los Estados pueden establecer mecanismos de control de ingreso a su territorio y salida de él con respecto a personas que no sean nacionales, siempre que dichas políticas sean compatibles con las normas de protección de los derechos humanos. En efecto, si bien los Estados guardan un ámbito de discrecionalidad al determinar sus políticas migratorias, los objetivos perseguidos por las mismas deben respetar los derechos humanos de las personas migrantes.

Pese a lo anterior, «los derechos humanos aparecen restringidos de facto a la ciudadanía nacional. Esto se manifiesta en el hecho de que la emigración aparece en la arena internacional como un tema de derechos humanos; mientras que la inmigración es considerada un asunto de soberanía nacional» (Delgado Hinostroza, 2013:93). Esa es una barrera para que las personas puedan ejercer su derecho humano a circular y a elegir su destino o residencia libremente.

${ }^{1}$ Según la CIDH, tales instrumentos son un conjunto de pactos, declaraciones, protocolos y convenciones donde se encuentran reconocidos los derechos humanos. Estos instrumentos han sido en su mayoría aceptados e incorporados por los Estados en sus normas internas y constituciones. Cabe aclarar que están por encima del poder estatal y, por lo tanto, los países tienen la obligación de cumplirlos. 
Alejandro Canales expresa que «la invisibilidad del aporte de los inmigrantes, de muchos de los costos y beneficios de la migración, así como de sus causas estructurales, redunda en una grave distorsión en el análisis y políticas orientados a la defensa y respeto de los derechos humanos y laborales de los inmigrantes» (2015:32). Muestra de ello son los migrantes en tránsito o en situación irregular que siguen sin ser valorados por ciertos Estados como agentes de derechos (Casillas, 2018), pues en primera instancia son invisibilizados e incluso criminalizados al juzgarlos sujetos vacíos de derechos al no tener una entrada por los canales institucionales a otra nación.

Es preciso tener en cuenta que la violación a los derechos humanos de los migrantes es una situación aún más grave para los indocumentados o en situación irregular, dado que se potencia el grado de vulnerabilidad ocasionado por la inseguridad que enfrentan o por la corrupción y la impunidad. Y, «además esa exposición no depende solamente de las leyes, sino también de factores - económicos, culturales y de política migratoria - que van desde las condiciones generales del país y las localidades» (Bobes, 2018:88).

Habría que sumar los obstáculos a que deben hacer frente los migrantes sin documentación en situación irregular para regresar a sus Estados de origen. De igual modo, el desprecio por el migrante ilegal está inspirado en el temor irracional a perder el bienestar, en el nacionalismo, el racismo o en el más básico temor a la diferencia cultural; es una producción social sostenida en la ignorancia con relación a las consecuencias que tienen los flujos migratorios para las sociedades receptoras (Thayer, 2016).

Según el peso específico de los derechos de los migrantes, Cecilia Bobes explica: «El derecho a la vida y la integridad personal —el más básico de todos que incluye el derecho a la dignidad, a no ser objeto de tortura ni tratos crueles, a no ser víctima de trata de personas, ni de detención arbitraria, etcétera» (2018:87). Por su parte, Luis Díaz Müller indica que los principales derechos humanos que los migrantes ven afectados son, «en primer lugar, la dignidad humana; segundo, la discriminación; en tercero, el racismo; en cuarto, la violencia y la pobreza; y quinto, los derechos sociales, salud, educación, vivienda, por citar sólo algunos» (2003:144). Además, se enfrentan a situaciones de vulnerabilidad y violación a derechos que rebasan el ámbito jurídico, de acuerdo con lo expuesto por Jorge Schiavon y Gabriela Díaz Prieto: 
1. Falta de acceso a la justicia a víctimas o testigos de un delito. No sólo deben contar con información relativa a sus derechos, sino los mecanismos para hacerlos valer, el nombre de la autoridad a la cual hacerle el reclamo, su ubicación, los tiempos que disponen para llevarlos a cabo, entre otros. En segundo lugar, se requiere de una asesoría jurídica de calidad; así como el tiempo y el dinero para sufragar los costos legales.

2. Debido proceso. En muchos casos los agentes migratorios no se identifican apropiadamente y no informan a los migrantes de sus derechos, los cuales incluyen ser notificados de los mecanismos de denuncia y de protección de sus consulados e instancias de apoyo nacional e internacional. Resulta indispensable llevar a cabo una entrevista en su idioma materno para explorar situaciones de trata, temor fundado de regresar al país de origen (solicitantes de asilo) y la posibilidad de legal estancia o regularización.

3. Secuestro y extorsión por parte del crimen organizado. Los integrantes de las bandas delictivas torturan a los migrantes para conseguir teléfonos de sus familiares a quienes piden un rescate; si no lo obtienen los asesinan, desaparecen o los integran a las filas de la banda delincuencial (2011:20-21).

\section{4}

Concerniente a los trabajadores migratorios, el Estado está obligado a garantizar el derecho a la igualdad y no discriminación, que comprende contar con políticas y legislación que los proteja frente a las relaciones laborales establecidas con empresas privadas o con el Estado, que actúa como empleador.

De esa manera, la orientación de las políticas de respeto a los derechos humanos de las personas migrantes debe asegurarse de la promoción y protección de todos los derechos humanos, civiles, políticos, económicos, sociales y culturales, incluido el derecho al desarrollo. Los Estados tienen una tarea permanente de garantizar el ejercicio y goce de sus derechos a toda persona migrante (cualquiera que sea su condición jurídica) que se encuentre bajo su jurisdicción, sin discriminación alguna por su regular o irregular estancia, nacionalidad, raza, género o alguna otra causa.

Ante las violaciones ya materializadas de derechos humanos de las personas migrantes, se debe atacar la impunidad para que no se repitan y luchar contra los factores culturales que justifican estos hechos, o la falta de acceso a las estructuras de justicia o impedimentos normativos. 
La formación y la evolución de los Estados modernos y el control de las migraciones se han construido paralelamente. Antes del siglo XVIII las fronteras no estaban sujetas a una gestión generalizada y sistemática. Los Estados aún no habían instaurado los sistemas formales de control fronterizo altamente burocratizados que se convirtieron en un rasgo característico del mundo contemporáneo (Kivisto y Faist, 2010). ${ }^{2}$ En esa línea, Saskia Sassen (2013) explica que la categoría de inmigrante era construida de forma diferente a la actual porque la cuestión de control fronterizo no tenía un carácter central para la soberanía estatal como después de la Primera Guerra Mundial. Dicha centralidad emerge en parte como función del desarrollo de la capacidad del Estado para controlar plenamente sus fronteras y su territorio.

Así, en pleno siglo XXI, «el control de la inmigración se ha convertido en una importante cuestión política. La mayoría de los Estados receptores están sumamente preocupados por la porosidad percibida de sus fronteras a los flujos de migrantes indocumentados y están arbitrando nuevas medidas para vigilarlas" (Pécoud y De Guchteneire, 2008:15). Éste ha sido un proceso de construcción de barreras selectivas a la migración que ha evolucionado y ha propiciado un ambiente más restrictivo para la migración no calificada.

Además, existen diferentes justificaciones para el control de fronteras enmarcadas en el temor a que esas personas migrantes transporten armas, drogas u enfermedades peligrosas no controladas; a que sean personas que rompan con los valores y la identidad cultural de la sociedad nativa; y que puedan formar parte del crimen organizado o del terrorismo. Por ello, «los gobiernos recurren cada vez más a las nuevas tecnologías para controlar sus fronteras y adoptan medidas más innovadoras para identificar a los migrantes indocumentados que se han introducido en sus territorios; al mismo tiempo, los Estados receptores tratan de alentar a los países de emigración y de tránsito a cooperar» (Pécoud y De Guchteneire, 2008:15).

\footnotetext{
${ }^{2}$ Peter Kivisto y Thomas Faist señalan que los precursores de elementos de control, como el sistema moderno de pasaportes, se remontan hasta el antiguo Egipto y el Imperio romano, aunque viajar a través de las fronteras sucedía con relativa informalidad y facilidad. El moderno sistema de pasaportes se dio con Luis XIV quien requirió papeles de identificación para todos los individuos que buscaran salir o entrar a Francia. El pasaporte reforzó la distinción entre ciudadanos y no ciudadanos, al mismo tiempo que sirvió para mejorar las capacidades de vigilancia de los Estados.
} 
Sin embargo, los controles externos no han sido suficientes para impedir el ingreso de personas migrantes, por lo que se incorporan las medidas internas con la intención de detectar a los migrantes indocumentados que han entrado en el país. Con frecuencia se prevén controles en el lugar de trabajo y el acceso de los migrantes indocumentados a los servicios sociales (Pécoud y De Guchteneire, 2008) hasta llegar a los propios domicilios. En opinión de Rens van Munster:

La ilegalización de los indocumentados, entonces, ha hecho posible que la inmigración indocumentada sea identificada, categorizada y gestionada como una población peligrosa. Con el indocumentado o la ilegalidad como elemento definitorio de su individualidad, los inmigrantes mal documentados son tratados de manera homogénea a pesar de que sus motivos, historias de vida y circunstancias pueden variar ampliamente (2009:31).

Este proceso de ilegalización del migrante exacerba la xenofobia y el distanciamiento del migrante de una sociedad receptora.

El concepto de securitización se incorporó a la literatura con el trabajo de Ole Wæver $(1995,1998)$ en el que definió la seguridad como un «acto de habla», mientras que la securitización se refiere a esa forma de representación lingüística que posicionó un problema particular como una amenaza existencial. El lenguaje es el que posiciona a actores (migrantes) o problemas específicos (flujos migratorios no controlados) como amenaza para una comunidad política. Por su parte, Thierry Balzacq brinda una definición más amplia de la securitización:

Un conjunto articulado de prácticas en las que los artefactos heurísticos (metáforas, herramientas políticas, repertorios de imágenes, analogías, estereotipos, emociones, etcétera) son movilizados contextualmente por un actor securitizador, cuyo objetivo es incitar a un público a construir una red coherente de repercusiones (sentimientos, sensaciones, pensamientos e intuiciones), en torno a la vulnerabilidad crítica de un objeto de referencia, que está de acuerdo con las razones del actor securitizador en sus elecciones y acciones, confiriendo al sujeto de referencia un aura de naturaleza amenazante sin precedentes hasta el punto de que se deba poner en marcha de inmediato una política personalizada a fin de bloquear su desarrollo (2011:3). 
La teoría de la securitización expone que es un acto de habla; es decir, conduce los problemas que tradicionalmente no serían temas de seguridad, como la migración, hacia la agenda de seguridad y permite que se tomen medidas extraordinarias. La Escuela de Copenhague ${ }^{3}$ es la más influyente en este tópico y se caracteriza por el rompimiento con un concepto básico de seguridad, en un contexto militar en defensa del Estado y como único actor, por uno nuevo que se compone de una agenda más amplia y al menos cuatro categorías adicionales: soberanía nacional (seguridad política), economías nacionales (seguridad económica), identidades colectivas (seguridad social) y especies y hábitats (seguridad ambiental) (Emmers, 2011).

Esta escuela también contribuye a profundizar los estudios de seguridad al incluir a actores que no sean parte del Estado (Does, 2013); estableció un espectro a lo largo del cual se pueden clasificar los asuntos públicos, que van desde los no politizados, los politizados y los actos de securitización (véase cuadro 1).

\section{CUADRO 1}

Espectro de la securitización

\begin{tabular}{|c|c|c|}
\hline No politizado & Politizado & Securitizado \\
\hline $\begin{array}{l}\text { El Estado no hace frente } \\
\text { al problema. }\end{array}$ & $\begin{array}{l}\text { El problema se maneja dentro } \\
\text { del sistema político estándar. }\end{array}$ & $\begin{array}{l}\text { El problema enmarcado como } \\
\text { una cuestión de seguridad a tra- } \\
\text { vés de un acto de secutirización. }\end{array}$ \\
\hline $\begin{array}{l}\text { El tema no está incluido } \\
\text { en el debate público. }\end{array}$ & $\begin{array}{l}\text { Es parte de la política pública que } \\
\text { requiere de la decisión del gobier- } \\
\text { no y la asignación de recursos o } \\
\text { más raramente, alguna forma de } \\
\text { gobernanza comunitaria (Buzan, } \\
\text { Wæver y De Wilde, 1998:23). }\end{array}$ & $\begin{array}{l}\text { Un actor de seguridad articula } \\
\text { un tema ya politizado como } \\
\text { una amenza existencial para un } \\
\text { objeto referente. }\end{array}$ \\
\hline
\end{tabular}

Fuente: Emmers (2011:138).

Al afirmar que un objeto referente está amenazado en su existencia, un actor de securitización reclama el derecho a medidas no ordinarias en aras de asegurar

${ }^{3}$ La Escuela de Copenhague, que surgió del Instituto de Investigación de Conflictos y Paz de Copenhague, encuentra sus raíces académicas en el libro de 1983 de Barry Buzan, Gente, Estados y miedo: el problema de la seguridad nacional en las relaciones internacionales. La escuela ha aportado varios conceptos al campo de los estudios de seguridad, sobre todo los de titulización y desecuritización. Mientras Ole Wæver formuló el concepto de titulización por primera vez a mediados de la década de 1990 (Wæver, 1995), Buzan, Wæver y De Wilde lo abordaron con mayor detalle en el libro Seguridad: un nuevo marco de análisis en 1998. 
la supervivencia de dicho objeto. El problema se extrae de la esfera de la política normal y es atendido con disposiciones extraordinarias; cabe aclarar que puede abordarse rápidamente y sin las reglas (legales) y regulaciones normales (democráticas) de la formulación de políticas para su atención.

La relevancia del marco de securitización es evidente en el caso de los inmigrantes y los solicitantes de asilo, el lenguaje utilizado al caracterizar a estas personas se plantea como una «amenaza» (a través del despliegue militar o el ajuste de los controles fronterizos) que son característicos de las prácticas tradicionales de seguridad (McDonald, 2008). Así, se justifican las medidas de emergencia y la suspensión de las reglas normales por un estado de excepción que paradójicamente se normaliza para esas personas. A pesar de ser una contribución innovadora, Matt McDonald hace una de las críticas más importantes a la teoría de la securitización:

La securitización tiene un marco estrecho en tres sentidos: primero, la forma de actuar que construye la seguridad es definida de forma limitada, con el foco en el discurso de los actores dominantes; en segundo lugar, el contexto del acto se define de manera limitada, con el foco sólo en el momento de intervención; finalmente, la naturaleza del acto se define únicamente en términos de la designación de amenazas (2008:1).

Es decir, la securitización, desde la Escuela de Copenhague, se ha centrado en el habla y se ha apartado de la realidad, además de verse como una abreviatura en la construcción de una agenda de seguridad funcional para los Estados.

En opinión de Sassen, «el control de las fronteras sigue siendo el mecanismo básico para regular la inmigración» (2013:202). No obstante, esto ha cambiado, los Estados buscan el control de la migración más allá de sus fronteras físicas, antes de que los migrantes y los posibles solicitantes de refugio lleguen a ellas. Tal situación conduce a nuevos mecanismos del control fronterizo que trascienden las fronteras tradicionales y que fijan nuevos objetivos con el propósito de incidir en las decisiones de política migratoria de los países vecinos y abrir el camino de las políticas de externalización.

\section{Orientación de fronteras expandidas y externalización migratoria}

Los atentados del 11 de septiembre de 2001 contra el World Trade Center, en Nueva York, y el Pentágono, motivaron un viraje en la política migratoria en 
Estados Unidos y en gran parte de los países receptores de migrantes (Martínez, 2008). Dichos acontecimientos demostraron que, lejos de estar debilitados por la creciente globalización, los Estados definen y aplican las políticas que estiman convenientes. Sin embargo, es evidente que la migración no puede gobernarse exclusivamente a partir de lo que ocurre al interior del territorio (Meyers y Papademetriou, 2002); el control de las propias fronteras es insuficiente y se reconoce la necesidad de ir más allá de las fronteras para contener la migración a través de diferentes mecanismos.

Después de estos acontecimientos, las medidas adoptadas por algunos Estados para apuntalar los controles fronterizos y con un cambio más restrictivo en las políticas migratorias dejaron a un lado las que a su consideración eran políticas laxas que habían dejado a las poblaciones nacionales vulnerables frente a peligros externos como la amenaza del terrorismo, a la que se sumaron con el tiempo el narcotráfico y la delincuencia organizada con la trata de personas. De ese modo, se identificó una amenaza desde fuera del territorio y particularmente se afectó a los inmigrantes al reconocerlos como un posible peligro para la seguridad nacional, más aún si estas personas no se podían identificar con un documento oficial o entraban en condiciones de ilegalidad.

Al respecto, Christina Boswell apunta que se «proporcionó una oportunidad para que los gobiernos, los políticos y los medios de comunicación correlacionen el terrorismo con la inmigración. Los inmigrantes se consideraron una amenaza para la seguridad, legitimando la introducción de medidas más draconianas para restringir y controlar la migración» (citada por Givens, Freeman y Leal, 2009:93). En consecuencia, se reforzó el argumento que legitima la externalización de las políticas migratorias a fin de salvaguardar la seguridad nacional, por lo que el derecho a migrar forma parte de la estructura de competencias soberanas, exclusivas y excluyentes, de los Estados.

En esa coyuntura surgió la idea de la dimensión externa de la política de inmigración, también definida como «externalización», "extraterritorialización» o «delegación» del control migratorio hacia terceros países (Gabrielli, 2017). Por su parte, Stock, Üstübici y Schultz consideran la externalización como «la extensión de los controles fronterizos y migratorios más allá de las llamadas «naciones receptoras de migrantes en el Norte global y hacia países vecinos o estados emisores en el Sur global» (2019:1). En tanto, para Gloria Naranjo Giraldo la idea de la externalización de las políticas migratorias se caracteriza por 
el hecho de que Estados receptores de migrantes implementan políticas de gestión de flujos migratorios fuera de sus propias fronteras. Esta estrategia implica la directa o indirecta cooperación de los Estados emisores o de tránsito. Está fundamentada en criterios como condicionar la ayuda al desarrollo para los "Estados en desarrollo», a su cooperación en la lucha contra la inmigración irregular; crear campos o centros para demandantes de asilo fuera de las fronteras de los Estados receptores; firmar acuerdos de readmisión y de cooperación policial con los países de origen y tránsito de los migrantes; intercambiando cuotas de migración legal (laboral) para los nacionales de los países que han aceptado el acuerdo (2014:18).

Además de la ayuda al desarrollo (Naranjo, 2014; Gabrielli, 2017) Bill Frelick, Ian M. Kysel y Jennifer Podkul (2016) aseveran que la externalización se formula a menudo engañosamente como un imperativo de seguridad y una acción humanitaria de uno o ambos, para salvar vidas en lugar de una estrategia de contención y control de la migración. Ello significa que en buena medida las políticas de externalización no son explícitas.

La externalización describe acciones estatales extraterritoriales con el propósito de evitar que migrantes y solicitantes de asilo ingresen a las jurisdicciones legales o territorios de países o regiones de destino, o hacerlos legalmente inadmisibles sin considerar individualmente los méritos de sus reclamaciones de protección. Éstas incluyen acciones unilaterales, bilaterales, y el compromiso estatal multilateral (Gammeltoft-Hansen, 2011), que pueden llevarse a cabo con diversos instrumentos: políticas de visado, sanciones, acuerdos de repatriación inmediata, campos de atención a solicitantes de refugio en terceros países y la tramitación de su solicitud de asilo fuera del territorio de destino.

En ese sentido, los países de destino pretenden alejarse de las responsabilidades como Estados democráticos protectores de derechos humanos y buscan una dimensión exterior que propone la transmisión de responsabilidades a terceros países, la cual puede o no estar respaldada por recursos económicos o por condicionantes para la obtención de recursos mediante tratados comerciales, apoyos para la modernización de la vigilancia fronteriza, control del crimen transnacional y la ayuda para el desarrollo. Todo lo anterior comprende lo que Aristide Zolberg (2003) ha denominado "políticas de control remoto», que implican el desplazamiento del lugar de control más allá del territorio común.

Las políticas de externalización migratoria son políticas llevadas a la práctica en el país emisor o de tránsito de población con el objetivo claro de contención 
de los flujos migratorios a partir de soluciones políticas fuera del territorio en aras de que los migrantes no lleguen al país de destino. De acuerdo con Apostolos Papadopoulos, es posible considerar al menos tres estrategias primordiales para externalizar las políticas de inmigración:

1. Control remoto: consiste en la transferencia del control de fronteras a terceros países o sus fronteras. 2. Protección remota: se pone el énfasis en la dimensión extraterritorial de protección de los refugiados. 3. Construcción de capacidades: en algunos países emisores y de tránsito que básicamente incluye transferencia de conocimiento, tecnología de vigilancia, equipamientos e instituciones (2007:98).

Por otro lado, la frontera se puede entender como «el resultado de un proceso dinámico, como una realidad construida política y socialmente y en permanente cambio en cuanto a su gestión de la movilidad humana» (Zapata, 2012:40).

Lorenzo Gabrielli (2017) argumenta que la externalización se construye con la delegación del control de los flujos migratorios hacia los principales países de tránsito, para crear una «zona tampón» y supuestamente disuadir la migración. Asimismo, la externalización se vincula con la ayuda al desarrollo que produce una clara reconfiguración geográfica de las prioridades de la ayuda, ya que los países que se encuentran a lo largo de las rutas migratorias más importantes se convierten en una prioridad.

Las políticas de externalización del control migratorio en terceros países propician una creciente responsabilización del control migratorio por medio de políticas e instrumentos implícitos y explícitos, lo que a su vez acarrea mayores riesgos a la integridad y violación a los derechos humanos de las personas migrantes y refugiados potenciales en su tránsito hacia un país de destino.

\section{Una perspectiva antihegemónica de las políticas migratorias desde el Sur global}

Después de la Segunda Guerra Mundial y cuando muchas de las sociedades colonizadas comenzaron a tener su independencia, surgió un gran interés académico sobre el desarrollo. Lemuel Ekedegwa Odeh (2010) expone que los estudiosos se preocuparon por el desarrollo comparativo y surgieron varios conceptos: «subdesarrollado» $y$ «desarrollado», «metrópoli» y «satélite», «centro» y 
"periferia», en un intento por clasificar a las sociedades según el nivel de su desarrollo económico. Al final de la Guerra Fría en 1991, los conceptos de Norte y Sur globales se introdujeron en el estudio comparativo sobre desarrollo entre naciones; mientras que el Norte global implica las economías desarrolladas, el Sur global ${ }^{4}$ implica las economías subdesarrolladas. ${ }^{5}$

En este devenir, Fernando Lozano Ascencio y Telésforo Ramírez García (2017) aclaran que el proceso de globalización ha contribuido a acrecentar las desigualdades económicas y sociales entre países y en el interior de éstos, lo que se expresa en una mayor concentración de la riqueza generada, un incremento de la polarización social y un aumento de la movilidad humana del Sur al Norte.

Una perspectiva desde el Sur global contribuye hacia un enfoque holístico de los procesos migratorios inmersos en una realidad de exclusión, violencia, pobreza y desigualdad, pues se considera que no puede sustituir la responsabilidad del Estado y la acción del mercado en la promoción del desarrollo económico y el bienestar de la población (Canales, 2015).

Es así como el debate sobre migración y desarrollo ha sido dominado por la visión del Norte global, que tiende a reducir los problemas clave de seguridad, control de flujos migratorios, integración en la sociedad receptora y remesas - entendido como el principal impulsor del desarrollo (Castles y Delgado, 2008). Esto ha derivado en políticas migratorias diseñadas bajo esa misma concepción de seguridad, control y manejo económico.

Desde la perspectiva tradicional del Norte global la migración es un fenómeno asociado con procesos económicos que hacen que los países de destino demanden una fuerza de trabajo para incrementar la mejora de la productividad y capitales, y a una racionalidad costo-beneficio, sobre todo del género masculino en edad productiva desde los países de origen: «Los Estados se rehúsan a crear sistemas de

\footnotetext{
${ }^{4}$ El primer uso del Sur global en un sentido político contemporáneo se produjo en 1969. Carl Oglesby escribió en la revista católica liberal Commonweal en una edición especial sobre la guerra de Vietnam: "Vietnamism has failed (...) The revolution can only be mauled, not defeated»; agregó que siglos de «dominación sobre el Sur global (...) han convergido (...)» (1969:90) para producir un orden social intolerable.

${ }^{5}$ Lemuel Ekedegwa Odeh expone que «mientras que el Norte global se caracteriza por una gran riqueza, gobernabilidad democrática, paz y estabilidad y constantemente propenso al progreso humano, el Sur global parece ser una zona de agitación, guerra, conflicto, pobreza, anarquía y tiranía. También las estructuras institucionales como reformas democráticas son bastante dispares entre el Norte y el Sur globales. Mientras que el Norte es rico, tecnológicamente avanzado, políticamente estable y envejecido ya que sus sociedades tienden a un crecimiento demográfico cero, lo contrario se encuentra en los países del Sur global» (2010:340).
} 
migración legales pese a una fuerte demanda de trabajadores por los empleadores, los migrantes experimentan altos niveles de riesgo y de explotación» (Castles, 2014:242).

Por su parte, Ronaldo Munck opina que «las políticas de inmigración actuales en los países del Norte son esencialmente una forma de lo que solía llamarse planificación nacional de la mano de obra. Son parte de la tendencia hacia el proteccionismo nacional que persiste (puede acentuarse) bajo la globalización» (2008:1239). Aún en esos casos los migrantes no han sido disuadidos en su decisión de llegar a un país que les ofrezca mejores condiciones de vida.

En efecto, la gestión de la migración exige mayores recursos - humanos, económicos y tecnológicos - para un proyecto que da lugar al proteccionismo, que defiende los privilegios de acceso, permanencia y salida en un circuito laboral, con repercusiones para los países que reducen la oferta de mano de obra y capacidades intelectuales, al menos potencialmente. Al respecto, Douglas S. Massey, Jorge Durand y Nolan J. Malone exponen que «los funcionarios públicos y académicos se han preocupado menos por los efectos de la emigración en los países de origen cuando el principal recurso que los emigrantes llevan consigo es el poder de su propia fuerza de trabajo» (2009:173). Dicha cuestión se transforma con la demanda creciente de migrantes calificados que puedan impulsar la innovación, la investigación y el desarrollo tecnológico en países de destino. Según Stephen Castles y Raúl Delgado Wise, una perspectiva antihegemónica desde el Sur global,

no debe caer en la simpleza de tener como tema central a los países de origen y tránsito, sino ir más allá, significa desarrollar un análisis exhaustivo que examine cada fenómeno específico (como la migración) en el amplio contexto de la dinámica general de las relaciones Norte-Sur, y las interacciones de los distintos niveles espaciales (local, regional, transnacional, etcétera) y áreas sociales (economía, cultura, política, etcétera) (2008:9).

La realidad actual desde el Sur global hace visibles a los que antes eran considerados simplemente «migrantes acompañantes», que cada vez son más mujeres (casi la mitad de los migrantes internacionales), niños y adolescentes, adultos mayores y familias que tienen una migración forzada. Desde el Sur global se tienen condiciones para migrar que trascienden el aspecto económico, las cuales van desde la reunificación familiar, el cambio climático que afecta sus comunidades, 
la violencia y pobreza extrema a la que se exponen, la persecución política, entre otras.

En este esquema, desde el Norte global se ha tratado de gestionar la migración y controlar los flujos migratorios. Al respecto, De Haas argumenta que «la noción de gestionar la migración es demasiado optimista y las políticas restrictivas de inmigración fallan, ya que ignoran y no pueden abordar las causas fundamentales de la migración» (2007:833). Por medio de las políticas de externalización se les exige a los países del Sur global una gestión de la migración eficiente y eficaz, que aumente sus capacidades en al menos cuatro rubros:

1. Recursos humanos. Con la contratación o asignación en tareas migratorias, ya sean agentes migratorios, policías o militares.

2. Recursos económicos. A través de presupuestos dirigidos a la contención, vigilancia y seguridad fronteriza, no necesariamente a la ayuda y cumplimiento de derechos civiles, económicos y sociales de las personas migrantes.

3. Recursos materiales y tecnológicos. Conlleva la creación y modernización de la infraestructura migratoria, nuevas tecnologías de la información y comunicaciones de control y verificación migratoria.

4. Cambios institucionales. Con la creación de organismos, reformas a los marcos legales, acuerdos o tratados internacionales, planes y programas migratorios, que respondan a lógicas de contención y seguridad fronteriza.

Si bien las responsabilidades de los Estados deben ser compartidas en aras de un desarrollo sostenible vinculado con una migración solidaria y responsable, Canales (2015) considera que la migración en los países de origen es vista como una oportunidad para potenciar sus procesos de desarrollo económico y social. Cabe mencionar que el debate se centra en los probables efectos y oportunidades de desarrollo que la migración pudiera significar y generar en esos países.

Por otro lado, los migrantes actuarían como agentes del cambio económico y social, dado que favorecen la innovación y transferencia de conocimiento y tecnología (De Haas, 2007). Las remesas tienen un gran potencial como instrumento para reducir la pobreza y promover el desarrollo. Sin embargo, «el Estado en los países de origen debe desempeñar un papel proactivo en la búsqueda de un desarrollo sostenible y mejora de la creación y el fortalecimiento de instituciones propicias para el desarrollo. Se debe tender a un desarrollo sostenible para que la migración se convierta en una opción, no en una necesidad» (Castles y Delgado, 2008:308). Las políticas estratégicas de los Estados deben enfocarse en la creación de un entorno económico y político propicio y más equitativo. 
Otras medidas se dirigen a mejorar la participación democrática, salvaguardar los derechos humanos y civiles, y mejorar la buena gobernanza (incluyendo a los migrantes y sus comunidades) en los procesos de planificación, gestión y toma de decisiones. Además, una estrategia más inteligente, de acuerdo con Massey, Durand y Malone, "sería la inclinación natural de los migrantes a quedarse en el exterior de manera temporal facilitándoles el regreso y la repatriación de fondos» (2009:177). Es claro que las remesas pueden contribuir a reducir la pobreza, pero no se les puede ver como sustituto de las políticas públicas orientadas a mejorar las condiciones de bienestar social de la población.

Es preciso tener en cuenta la cooperación entre Estados del Sur, asociaciones de migrantes y la sociedad civil que desempeñan una función cada vez más importante en la construcción de un régimen de migración internacional socialmente justo (Delgado Wise, 2018). Ello es esencial para definir problemas comunes, fomentar el intercambio, compartir buenas prácticas, negociar e identificar soluciones o mejores condiciones para la migración.

Los países de tránsito deben proveer seguridad y protección a todas las personas migrantes que atraviesan su territorio como si se tratase de nacionales. Los migrantes en tránsito son altamente vulnerables, pues enfrentan grandes peligros que atentan contra su salud física y mental y a veces ponen en riesgo su vida. Es prioritario mitigar esos riesgos, mediante la legislación, la acción institucional. También son relevantes la protección y asistencia a migrantes en tránsito con la posibilidad de ir y regresar con un registro oportuno en puntos migratorios preestablecidos, con el propósito de otorgar visas temporales y moverse por el país libremente, así como el aumento de visas otorgadas por razones humanitarias.

Desde el Sur global la emigración debe ser vista como un derecho, un acto libre y voluntario. Los beneficios que propicie deben ser compartidos entre los países involucrados, al igual que la responsabilidad política, social y económica para generar un cambio. Es pertinente reflexionar que el pensamiento del Sur global no excluye al pensamiento del Norte global, pues en palabras de Boaventura de Sousa Santos significa «incluir un panorama mucho más amplio de posibilidades epistemológicas y políticas. El objetivo de las epistemologías del Sur es posibilitar que los grupos sociales oprimidos representen al mundo como propio y en sus propios términos, pues sólo así podrán cambiarlo según sus propias aspiraciones» (2018:29).

La perspectiva del Sur global en la migración no es una condición geográfica, ni se trata de una visión unívoca de la realidad, se trata de una epistemología del 
Sur que replantea los desafíos para no ser reproductores de saberes que naturalicen desigualdades (De Sousa, 2018); esas relaciones disímiles que permiten en un Estado democrático tener evidentes contrastes entre nacionales y migrantes dentro de su territorio (incluso pareciera que estos últimos se hallan lejos de la aplicación positiva del derecho).

\section{Conclusiones}

Las reflexiones se enuncian a partir de la siguiente pregunta: ¿̇cómo entender las políticas migratorias con una perspectiva desde el Sur global? Mientras que el Norte global da prioridad a la seguridad, la soberanía y la salvaguarda de valores nacionales en los ámbitos social y cultural que los cohesionan, en tanto que debilitan su posición de garantes de derechos; en cambio, en el Sur global se refuerza la posición liberal de los gobiernos en defensa de los derechos humanos de los migrantes que han de prevalecer frente a las voluntades y los intereses de los Estados, con lo que contribuyen al pleno desarrollo y garantizan los derechos de las personas a vivir con dignidad, libres de violencia y miedo.

Para las migraciones la perspectiva del Sur global confronta un pensamiento reflexivo de la situación de los migrantes del Sur que enfrentan una mayor criminalización, xenofobia, exclusión y marginación. Por tanto, este pensamiento busca corregir dicha situación hasta llegar a un punto de igualdad de derechos, oportunidades y respeto; no como una concesión sino como una condición efectiva en circunstancias de por sí ya adversas.

Por otra parte, en los países del Sur global se ha puesto cuidado en mantener en la agenda pública un discurso gubernamental de responsabilidad frente a los derechos humanos de las personas migrantes, sin que se encuentre exento de fallas. En su mayoría, ese discurso se ha manifestado en políticas migratorias con una orientación hacia el respeto de los derechos humanos, pero que contrastan con la denominada gestión de la migración que se materializa con la actuación de las autoridades que se contradicen al detener masivamente a migrantes, hacinándolos en estaciones migratorias, sin garantizar el debido proceso y violando sus derechos humanos. Además, afectan a posibles solicitantes de refugio que son devueltos, pues los exponen a fuertes riesgos e incluso a perder la vida en escenarios de violencia. 
Uno de los objetivos primordiales de los países del Sur global debe ser la desecuritización de la migración; es decir, sacar de la agenda de seguridad a la migración para no criminalizar a los migrantes por el simple hecho de cruzar una frontera política; tal acción promovería un distanciamiento de la xenofobia y la discriminación. La externalización de las políticas de migración, vista desde el Sur global, representa una relación asimétrica que aparta a los países del Norte global de sus responsabilidades internacionales como Estados democráticos y a los del Sur, lejos de crear canales de corresponsabilidad migratoria, en realidad los obliga o somete a cumplir con responsabilidades que van más allá de sus capacidades institucionales. Esto se logra mediante una serie de presiones unilaterales (económicas y políticas) que pretenden modificar los flujos migratorios.

En el Sur global es viable pensar en una política migratoria solidaria acorde con los principios que sustentan un Estado democrático. Ello implica el respeto a la dignidad de todo ciudadano y en el mismo sentido reconocer al migrante como ser humano con derechos intrínsecos, con capacidades y potencialidades de desarrollo iguales a los demás.

A los países del Sur global corresponde materializar una agenda de fronteras accesibles y de derechos humanos, abrir los canales de una migración circular, con oportunidades abiertas de retorno responsable a los países de origen y de vuelta a los países de destino, así como de cooperación entre las naciones del Sur. Es pertinente que los diferentes espacios del Sur global aprecien de otra manera las políticas migratorias, para asumir una política de responsabilidad propia en principio, pero también compartida. Finalmente, cabe recordar lo que afirma Javier de Lucas: «Somos animales migratorios, cruzamos fronteras» (2016:93). Y no cabe duda de que lo seguiremos haciendo.

\section{Referencias}

Alonso, José Antonio (junio, 2011), «Migración internacional y desarrollo: una revisión a la luz de la crisis», Naciones Unidas, Departamento de Estudios Económicos y Sociales, Background Paper no. 11.

Balzacq, Thierry (2011), "A theory of securitization: origins, core assumptions, and variants», en Thierry Balzacq (ed.), Securitization theory: how security problems emerge and dissolve, New York, Routledge, pp. 1-30. 
Bobes León, Cecilia (ed.) (2018), Politica migratoria y derechos de los migrantes en México, México, Facultad Latinoamericana de Ciencias Sociales.

Boutros-Ghali, Boutros (1995), "Democracy: a newly recognized imperative», Global governance, 1(1), pp. 3-11, en http://www.jstor.org.pbidi.unam.mx:8080/stable/278 00098

Buzan, Barry, Ole Wæver y Jaap de Wilde (1998), Security. A new framework for analysis, Colorado, Lynne Rienner Publishers.

Canales, Alejandro (2015), El debate sobre la migración y desarrollo. Evidencias y aportes desde América Latina, México, Universidad de Guadalajara, en https://lasa. international.pitt.edu/LARR/prot/fulltext/vol50no1/50-1_29-53_canales.pdf

Casillas R., Rodolfo (2018), «Convergencias y divergencias en los marcos jurídicos de los países del norte centroamericano, México y Estados Unidos, en materia de tráfico de migrantes», Migración y Desarrollo, 16(30), pp. 95-121, en http://www. scielo.org.mx/scielo.php?script $=$ sci_arttext\&pid $=$ S1870-75992018000100095\&lng $=e s \& \ln g=e s$

Castles, Stephen (2014), "Las fuerzas tras la migración global», Revista Mexicana de Ciencias Politicas y Sociales, 59(220), pp. 235-260, en http://www.scielo.org.mx/ scielo.php?script $=$ sci_arttext\&pid=S0185-19182014000100008\&lng $=$ es\&tlng=es

Castles, Stephen y Raúl Delgado Wise (eds.) (2008), Migration and development. Perspectives from the South, Geneva, International Organization for Migration.

Czaika, Mathias y Hein de Haas (2013), "The effectiveness of immigration policies», Population and Development Review, 39(3), pp. 487-508.

Corte Interamericana de Derechos Humanos (17 de septiembre de 2003), "Condición jurídica y derechos de los migrantes indocumentados», Opinión Consultiva OC18/03, Serie A no. 18.

De Haas, Hein (2007), «Turning the tide? Why development will not stop migration», Development and Change, 38(5), pp. 819-841.

Delgado Hinostroza, Pedro P. (2013), Apátridas, refugiados y migrantes: el derecho a la libre circulación, México, Fondo de Cultura Económica.

Delgado Wise, Raúl (2018), «Is there a space for counterhegemonic participation? Civil society in the global governance of migration", Globalizations, 15, pp. 746-761.

De Lucas, Javier (2016), «Refugiados e inmigrantes: por un cambio en las políticas migratorias y de asilo», Revista de Pensamiento Contemporáneo (50), pp. 92-113.

De Sousa Santos, Boaventura (2018), "Introducción a las Epistemologías del Sur», en Maria Paula Meneses y Karina Bidaseca, Epistemologías del Sur. Epistemologias do Sul, Buenos Aires, Consejo Latinoamericano de Ciencias Sociales/Centro de Estudos 
Sociais-Universidade de Coimbra, pp. 25-61, en http://biblioteca.clacso.edu.ar/ clacso/se/20181124092336/Epistemologias_del_sur_2018.pdf

Díaz Müller, Luis T. (2003), "Migraciones y derechos humanos: el caso de los trabajadores mexicanos indocumentados», en Paz Consuelo Márquez Padilla, German Pérez Fernández y Remedios Gómez Arnau (coords.), Desde el Sur: visiones de Estados Unidos y Canadá desde América Latina a principios del siglo XXI, México, Centro de Investigaciones sobre América del Norte-Universidad Nacional Autónoma de México.

Does, Antonia (2013), The construction of the maras: between politicization and securitization, Genève, Graduate Institute Publications, en http://books.openedition.org/iheid/716 Emmers, Ralf (2011), «Securitization», en Alan Collins (ed.), Contemporary security studies, New York, Oxford University Press.

Frelick, Bill, Ian M. Kysel y Jennifer Podkul (2016), «The impact of externalization of migration controls on the rights of asylum seekers and other migrants», Migration and Human Security Center for Migration Studies of New York, 4(4), pp. 190-220.

Gabrielli, Lorenzo (2017), «La externalización europea del control migratorio: żla acción española como modelo?», Anuario CIDOB de la Inmigración 2017.

Gammeltoft-Hansen, Thomas (2011), Access to asylum: international refugee law and the globalization of migration control, Cambridge, Cambridge University Press.

Givens Terri, Fary Freeman y David Leal (2009), Immigration policy and security: U.S., European, and Commonwealth perspectives, Estados Unidos, Routledge.

Kivisto Peter y Thomas Faist (2010), Beyond a border: the causes and consequences of contemporary inmigration, Estados Unidos, Pine Forge Press.

Lozano Ascencio, Fernando y Telésforo Ramírez García (julio-diciembre, 2017), «Desigualdad global y migración calificada de México a Estados Unidos», Carta Económica Regional, 29(120).

Mármora, Lelio (2002), Las políticas de migraciones internacionales, Argentina, Organización Internacional para las Migraciones/Paidós.

Martínez Pizarro, Jorge (ed.) (2008), América Latina y el Caribe: migración internacional, derechos humanos y desarrollo, Chile, Comisión Económica para América Latina y el Caribe.

Massey, Douglas S., Jorge Durand y Nolan J. Malone (2009), Detrás de la trama: políticas migratorias entre México y Estados Unidos, México, Universidad Autónoma de Zacatecas/Miguel Ángel Porrúa.

Meyers, Deborah W. y Demetrious Papademetriou (2002), «Un nuevo contexto para la relación migratoria de México y Estados Unidos», Foreign Affairs, 2(1). 
McDonald, Matt (diciembre de 2008), «Securitization and the construction of security article ", European Journal of International Relations, en https://journals.sagepub. com/doi/10.1177/1354066108097553

Mora, David (2013), "Metodología para la investigación de las migraciones», Integra Educativa, VI(1).

Munck, Ronaldo (2008), "Globalisation, governance and migration: an introduction», Third World Quarterly, 29(7), pp. 1227-1246, en http://www.jstor.org.pbidi.unam. mx:8080/stable/20455107

Naranjo Giraldo, Gloria Elena (2014), «Desterritorialización de fronteras y externalización de políticas migratorias. Flujos migratorios irregulares y control de las fronteras exteriores en la frontera España-Marruecos», Estudios Politicos, o(45), pp. 1332, en https://aprendeenlinea.udea.edu.co/revistas/index.php/estudiospoliticos/ article/view/20194

Odeh, Lemuel Ekedegwa (2010), "A comparative analysis of global North and global South economies», Journal of Sustainable Development in Africa, 12(3), en https:// pdfs.semanticscholar.org/3629/a2898d4dc51902de3b8bd6b1c3b553fe7fff.pdf

Organización Internacional del Trabajo y Organización de las Naciones Unidas (2015). «Migración, derechos humanos y gobernanza. Manual para Parlamentarios no. 24», en https://www.ohchr.org/Documents/Publications/MigrationHR_and_Gover nance _HR_PUB_ $15{ }_{-}{ }_{-}$_SP.pdf

Pécoud, Antoine y Paul de Guchteneire (2008), Migración sin fronteras: ensayos sobre la libre circulación de las personas, Francia, Organización de las Naciones Unidas para la Educación, la Ciencia y la Cultura.

Papadopoulos, Apostolos (2007), «Editorial: migration and human security in the Balkans", Migration Letters, 4(2), pp. 95-100.

Sassen, Saskia (2013), Inmigrantes y ciudadanos: de las migraciones masivas a la Europa fortaleza, España, Siglo XXI.

Schiavon, Jorge y Gabriela Díaz Prieto (2011), Los derechos humanos de las personas migrantes en México: estudio de caso para promover su respeto y defensa, México, Centro de Investigación y Docencia Económicas.

Stock, Inka, Aysen Üstübici y Susanne U. Schultz (2019), «Externalization at work: responses to migration policies from the Global South», Comparative Migration Studies, 7(48), en https://doi.org/10.1186/s40878-019-0157-z

Thayer, Luis Eduardo (2016), «Migración, Estado y seguridad», Polis, 44, en http:// journals.openedition.org/polis/11854 
Van Munster, Rens (2009), Securitizing immigration: the politics of risk in the EU, Inglaterra, Palgrave Macmillan.

Wæver, Ole (1995), «Securitization and desecuritization», in Ronnie D. Lipschutz (ed.), On Security, New York, Columbia University Press, pp. 46-86.

Wæver, Ole (1998), «Insecurity, security and asecurity in the West European non-war community», en Emmanuel Adler y Michael Barnett (eds.), Security Communities, Cambridge, Cambridge University Press, pp. 69-118.

Zapata Barrero, Ricard y Xavier Ferrer-Gallardo (eds.) (2012), Fronteras en movimiento: migraciones hacia la Unión Europea en el contexto mediterráneo, España, Bella Terra.

Zolberg, Aristide (2003), «The archaeology of «Remote Control», en Andreas Fahrmeir, Olivier Faron y Patrick Weil (eds.), Migration control in the North Atlantic World: the evolution of State practices in Europe and the United States from the French Revolution to the inter-war period, New York, Berghan Books, pp. 195-222. 